\title{
LA-UR-21-21777
}

Approved for public release; distribution is unlimited.

Title: $\quad$ Strongly-coupled Physics Through a Conformal Field Theory Lens (IC project w20_strongcftlens)

Author(s): $\quad$ Stergiou, Andreas

Intended for: Report

Issued: 
Disclaimer:

Los Alamos National Laboratory, an affirmative action/equal opportunity employer, is operated by Triad National Security, LLC for the National Nuclear Security Administration of U.S. Department of Energy under contract 89233218CNA000001. By approving this article, the publisher recognizes that the U.S. Government retains nonexclusive, royalty-free license to publish or reproduce the published form of this contribution, or to allow others to do so, for U.S. Government purposes. Los Alamos National Laboratory requests that the publisher identify this article as work performed under the auspices of the U.S. Department of Energy. Los Alamos National Laboratory strongly supports academic freedom and a researcher's right to publish; as an institution, however, the Laboratory does not endorse the viewpoint of a publication or guarantee its technical correctness. 


\section{Strongly-coupled Physics Through a Conformal Field Theory Lens}

w20_strongcftlens

Progress Report 1

Andreas Stergiou 


\section{$\mathrm{O}(2) \times \mathrm{O}(20)$ chiral and antichiral islands}

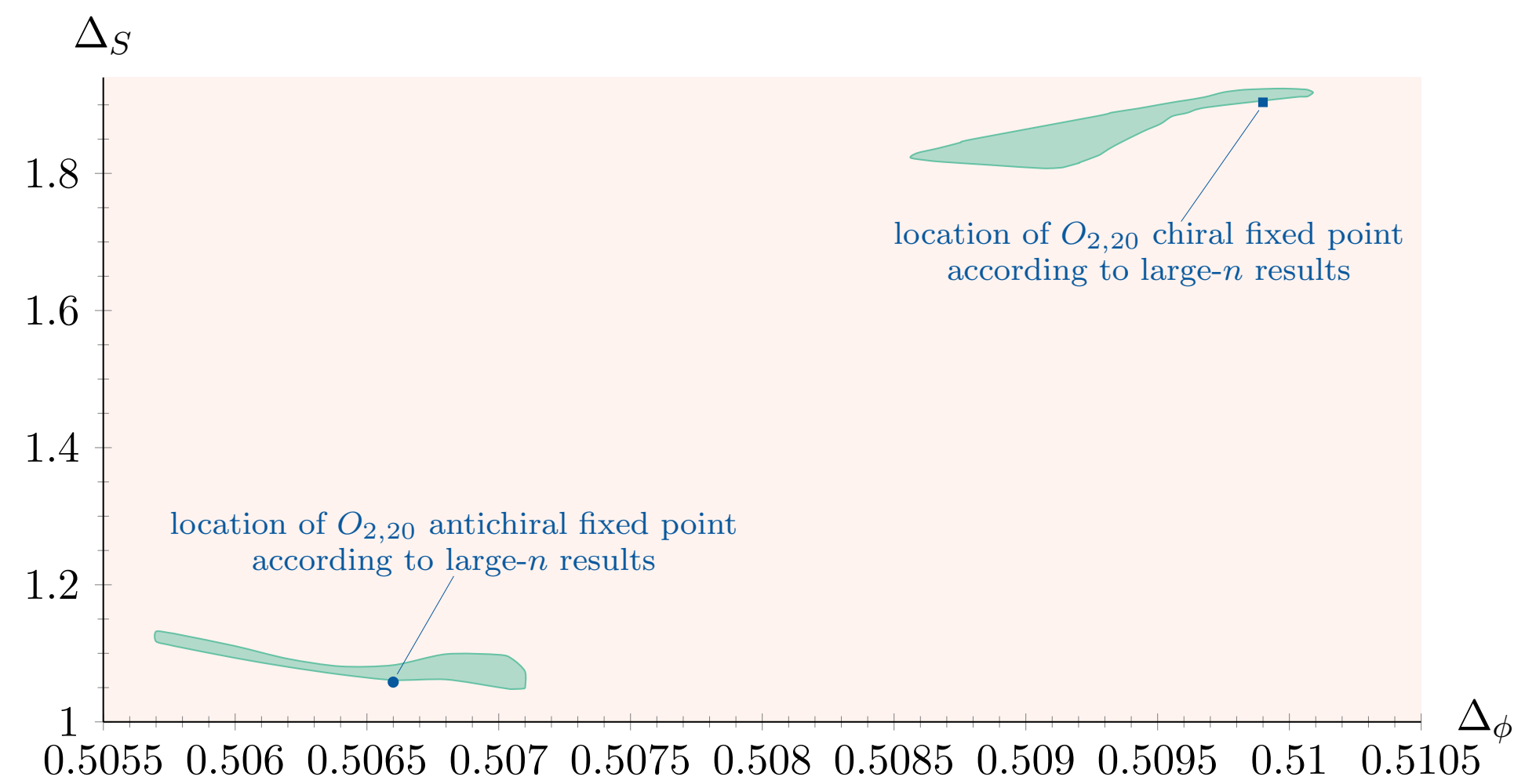

Allowed region (in green) for the $\mathrm{O}(2) \times \mathrm{O}(20)$ chiral and antichiral fixed points according to bootstrap computations run on Badger, as well as their location according to older methods. (Fig. 7 of arXiv:2004.14388.) 


\section{$\mathrm{O}(2) \times \mathrm{O}(6)$ chiral island}

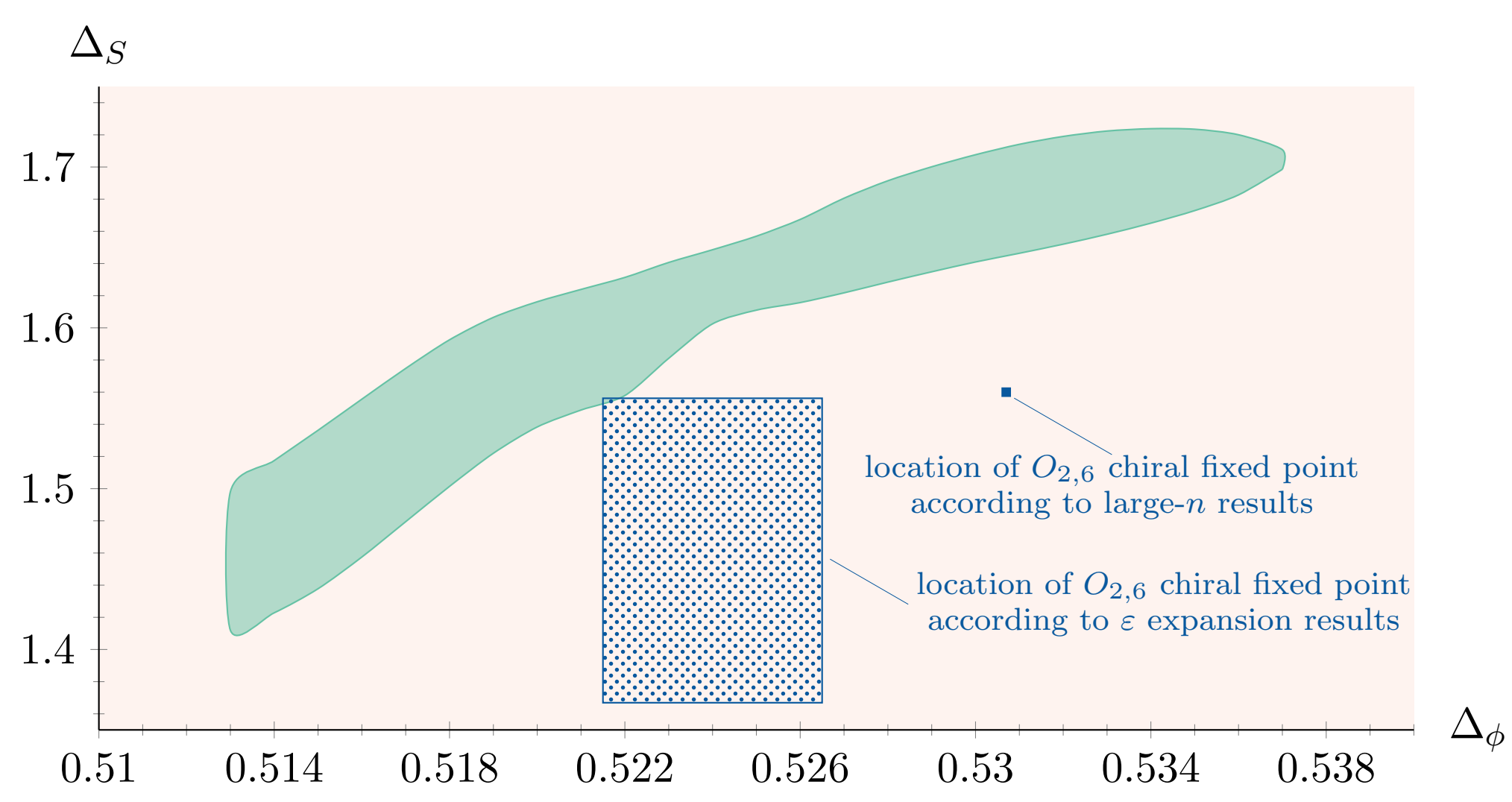

Allowed region (in green) for the $\mathrm{O}(2) \times \mathrm{O}(6)$ chiral fixed point according to bootstrap computations run on Badger, as well as its location according to older methods. (Fig. 9 of arXiv:2004.14388.) 


\section{Fixed points in the $\varepsilon$ expansion}

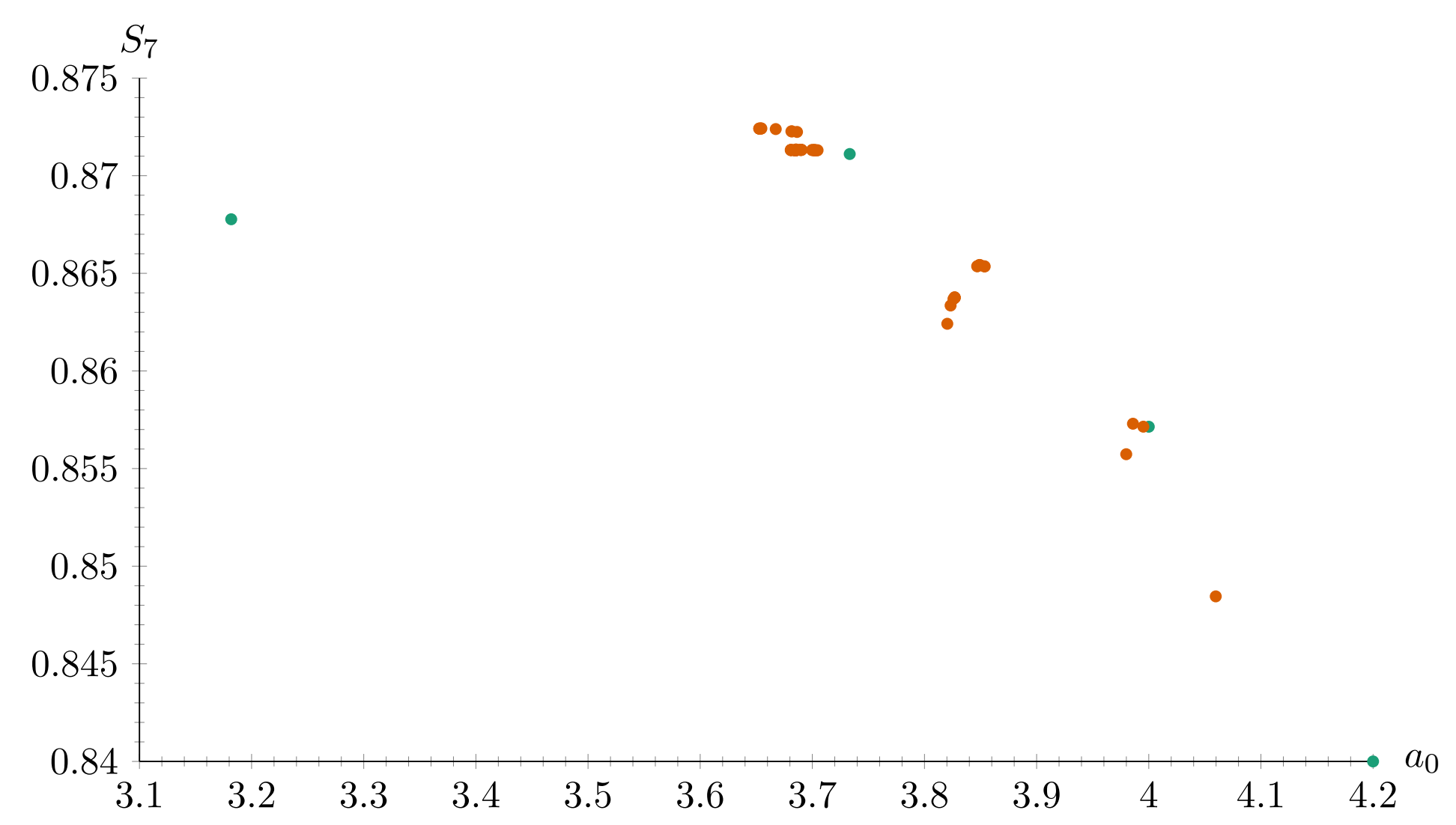

Locations of fixed points obtained with nonlinear constrained optimization on Badger (green:rational, orange: irrational). Most of these fixed points are new. (Fig. 4 of arXiv:2010.15915.) 


\section{Pairs of kinks in MN theories}

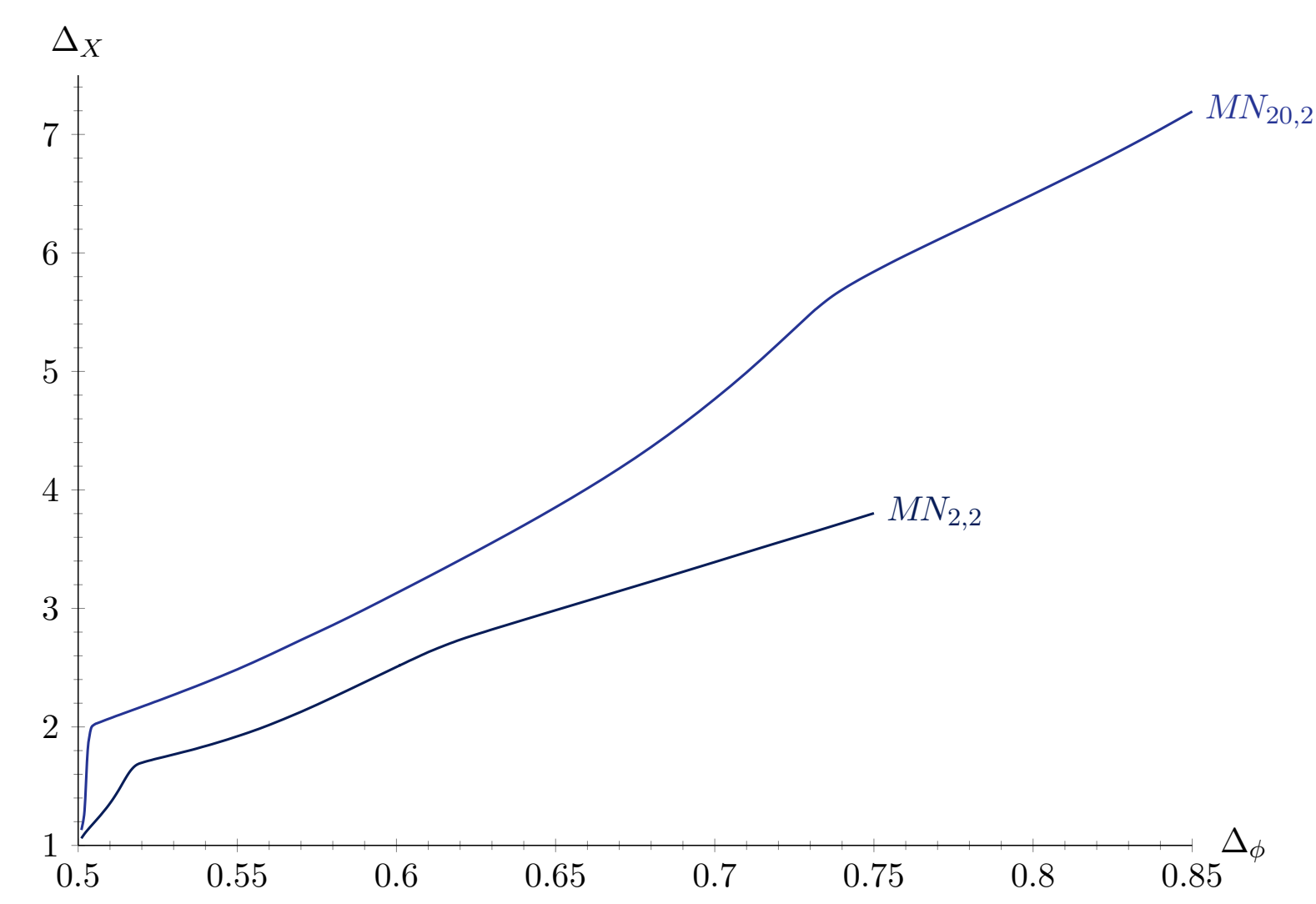

Kinks in bootstrap bounds according to bootstrap computations run on Badger, marking the existence of two fixed points for each theory (one known, the other new). (Fig. 1 of arXiv:2101.08788.) 


\section{Kinks in MN theories}

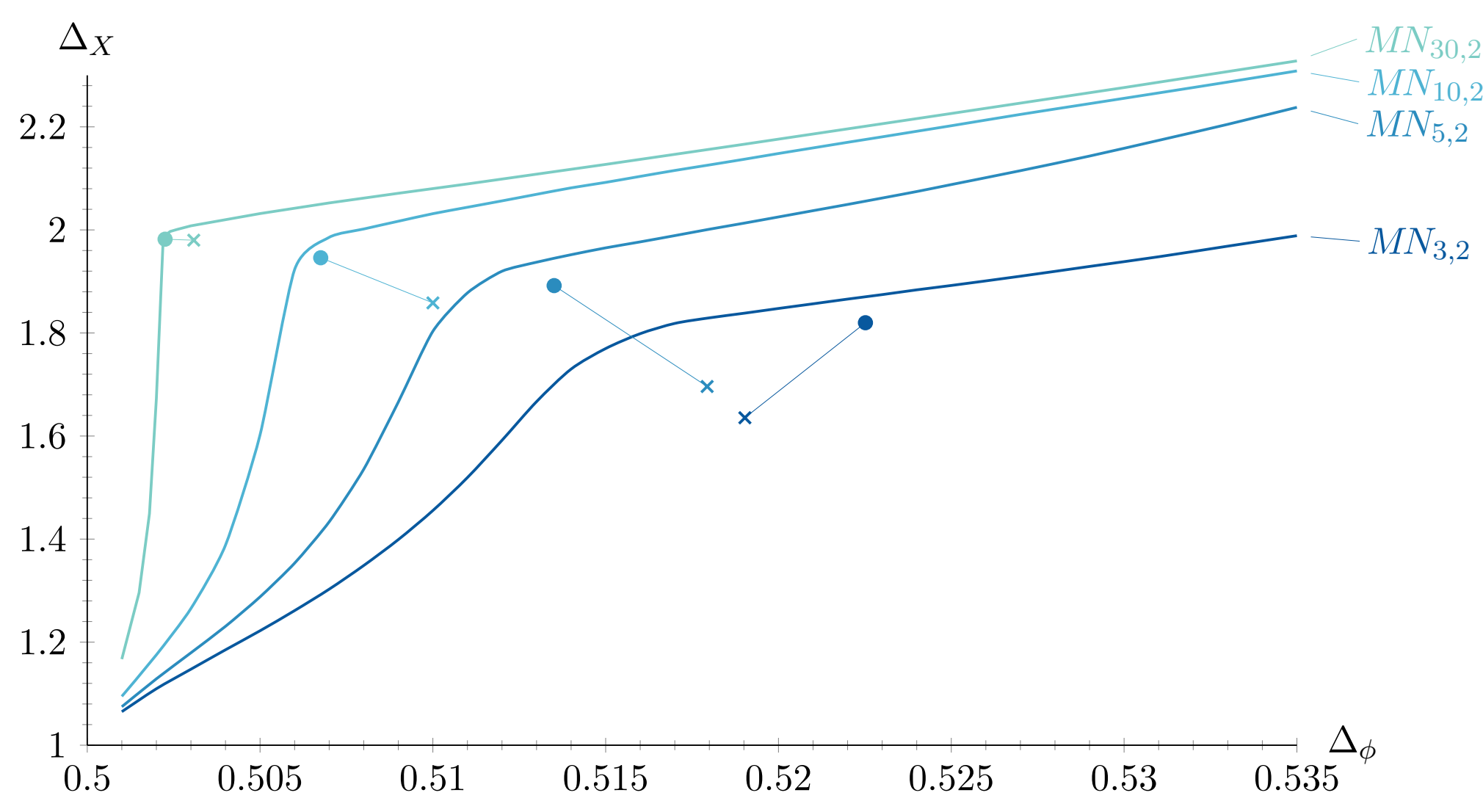

Kinks in bootstrap bounds signifying the existence of fixed points according to bootstrap computations run on Badger, as well as their locations according to older methods. (Fig. 2 of arXiv:2101.08788.) 